\title{
AS CARACTERÍSTICAS DOS ALUNOS SÃO DETERMINANTES PARA O ADOECIMENTO DE PROFESSORES - UM ESTUDO COMPARATIVO SOBRE A INCIDÊNCIA DE BURNOUT EM PROFESSORES DO ENSINO REGULAR E ESPECIAL ${ }^{1}$
} THE STUDENT CHARACTERISTICS AFFECT TEACHERS' ILLNESSES - A COMPARATIVE STUDY ON THE INCIDENCE OF BURNOUT IN REGULAR AND SPECIAL EDUCATION TEACHERS

\author{
Nilson Rogério da SILVA ${ }^{2}$ \\ Maria Amélia ALMEIDA ${ }^{3}$
}

\begin{abstract}
RESUMO: o exercício da docência é permeado por condições de trabalho adversas, baixos salários, insuficiência de recursos materiais e didáticos, salas numerosas, tensão no relacionamento com os alunos, carga horária de trabalho excessiva, inexpressiva participação no planejamento da instituição e nas políticas institucionais e falta de segurança no ambiente escolar. O presente estudo teve por objetivo comparar a presença de indicadores de burnout em três grupos de professores que atuam no primeiro ciclo do Ensino Fundamental: a) 20 no ensino regular, em turmas sem a inserção de alunos com necessidades educacionais especiais - RSI; b) 20 no ensino regular, em turmas com a inserção de alunos com necessidades educacionais especiais - RCI; c) 20 em salas de recursos - SR. Para a coleta, foi utilizado o Maslach Burnout Inventory -MBI. Na análise de dados, empregou-se o SPSS, versão 13.0, e o Teste de Kruskal-Wallis para comparação dos grupos. Os resultados, que foram organizados em forma de Figuras e Tabelas, revelam que, de maneira geral, os grupos apresentaram relativa similaridade. Entretanto, algumas diferenças foram encontradas. O grupo de professores SR obteve os melhores resultados na avaliação das três escalas do burnout, quando comparado com RSI e RCI, ou seja, com predominância de respostas nos níveis mais baixos de exaustão emocional, altos na diminuição da realização pessoal e baixos para despersonalização. Espera-se que os dados expostos contribuam para a compreensão do burnout em professores do ensino regular com e sem inclusão de alunos com necessidades educacionais especiais, e/ou suscitem novos encaminhamentos de pesquisas.
\end{abstract}

PALAVRAS-CHAVE: Educação Especial. Ensino Regular. Professores. Ensino Fundamental. Indicadores de Burnout.

\begin{abstract}
The practice of teaching is permeated by adverse working conditions, low wages, inadequacy of material and teaching resources, overcrowded classrooms, tension in relationships with the students, excessive work load, lack of safety in the school environment, insignificant participation in institutional planning and in institutional politics. The objective of the present study was to compare burnout among three groups of teachers who work in elementary grades: a) 20 teachers who teach in regular school classrooms without the inclusion of students with special educational needs - RSI Group; b) 20 teachers who teach in the regular classroom with special needs students - RCI Group; c) 20 teachers who teach in resource classrooms (SR Group). The instruments used for data collection were the Maslach Burnout Inventory -MBI. The data was analyzed by SPSS version 13.0 and Kruskal-Wallis test for comparison of the three groups. The results were organized in the form of figures and tables. In general, the results demonstrated that the groups presented relative similarity. The teachers from the SR Group obtained the best results in the evaluation of the three burnout scales when compared to the RSI Group and RCI Group, that is, there was a prevalence of answers in the lower levels of emotional exhaustion, high level of low personal accomplishment and low level for depersonalization. It is hoped that these results contribute to a better understanding of burnout in teachers from regular classrooms with or without students with educational special needs and/or to indicate new directions for investigation.
\end{abstract}

KEYWORDS: Special Education. Regular Teaching. Elementary School Teachers. Burnout.

\footnotetext{
1 Trata-se de um texto que apresenta parte dos dados de Tese de Doutorado, a qual recebeu apoio financeiro da FAPESP e FUNDUNESP.

2 Departamento de Educação Especial - Faculdade de Filosofia e Ciências, Universidade Estadual Paulista Unesp Campus de Marília. nilson@marilia.unesp.br

${ }^{3}$ Programa de Pós-Graduação em Educação Especial, Universidade Federal de São Carlos - UFSCar. ameliama@ terra.com.br
} 


\section{INTRODUÇÃO}

A síndrome de burnout é definida como uma resposta ao stress laboral crônico, que envolve condutas negativas em relação às pessoas e ao trabalho, além de atitudes e sentimentos que podem acarretar problemas ao trabalhador e à organização do trabalho (CODO; VASQUES-MENEZES, 2006). Ainda segundo esses autores, devido à síndrome, o trabalhador perde o sentido de sua relação com o trabalho. Em decorrência, nada mais lhe importa e qualquer esforço parece inútil.

O burnout pode ser entendido como um tipo especial de stress ocupacional crônico, marcado pela presença de frustração e exaustão com o trabalho, cuja evolução é gradual e pode afetar todas as esferas da vida da pessoa (REINHOLD, 2007).

A síndrome do burnout é um fenômeno de incidência mundial, e o exercício profissional de professores é permeado por situações que oferecem riscos à saúde física e emocional. Maslach e Jackson (1981) consideram o burnout uma resposta principalmente emocional, sublinhando os fatores de trabalho e os institucionais como condicionantes e antecedentes da síndrome.

A incidência de burnout nos vários países ainda é pautada na incerteza, mas dados sugerem um número significativo de indivíduos acometidos, que pode variar entre $4 \%$ a $85,7 \%$, dependendo da população estudada (TRIGO; TENG; HALLAK, 2007).

Os profissionais mais suscetíveis à síndrome são os que trabalham na área assistencial, em contato constante e direto com sua clientela na prestação de serviço, como profissionais de educação e saúde (VOLPATO et al., 2003; CODO; VASQUES-MENEZES, 2006).

Existem quatro concepções teóricas que buscam a etiologia da síndrome: a clínica, a sociopsicológica, a organizacional e a sócio-histórica (MUROFUSE; ABRANTES; NAPOLEÃO, 2005). A concepção sociopsicológica é a mais adotada, em grande parte motivada pela difusão em todo o mundo do instrumento MBI (Maslach Burnout Inventory) desenvolvido por Maslach e Jackson (1981), com traduções e validações em diversos países, inclusive o Brasil. Para esta concepção, o burnout decorre da interação de características individuais, fatores ambientais e os aspectos do trabalho.

Nesta concepção, o burnout tem sido entendido como uma resposta ao stress crônico e compreende três dimensões: exaustão emocional, diminuição da realização pessoal e despersonalização (MASLACH; JACKSON, 1981).

Maslach e Jackson (1981) caracterizam essas três dimensões:

1. Exaustão emocional: nessa dimensão, o indivíduo falhou, ao tentar combater os agentes estressores, ocorrendo uma perda progressiva de energia. Essa ausência de energia leva a um esgotamento físico e mental. A necessidade de disponibilidade afetiva para a vinculação e o consequente desenvolvimento 
do trabalho e a impossibilidade de concretizá-las levam a um desgaste e a um sentimento de exaustão emocional;

2. Despersonalização: o indivíduo não se importa mais em atingir seus objetivos e cumprir suas metas, relacionando-se friamente com as outras pessoas. Essa fase caracteriza-se por cinismo, ironia, insensibilidade, sentimentos negativos e irritabilidade. O indivíduo passa a tratar as pessoas a seu redor como se fossem objetos;

3. Diminuição da realização pessoal: nessa fase, o sentimento de frustração, arrependimento e insatisfação fazem parte da vida do sujeito, julgando-se incapaz de cumprir com as demandas. Falta motivação para prosseguir com seu trabalho e tornam-se presentes sensações de menor rendimento, insatisfação com o seu desenvolvimento profissional e um sentimento de inadequação no trabalho. A autoestima e autoconfiança desaparecem.

Maslach, Schaufeli e Leiter (2001) consideram o burnout um fenômeno psicossocial, que surge como uma resposta crônica aos estressores interpessoais ocorridos na situação de trabalho, sendo uma experiência individual e circunscrita ao contexto do trabalho.

Demerouti et al. (2001) encontraram uma associação entre alta demanda no trabalho e a elevada incidência dos indicadores de burnout. Stansfeld et al. (1997) identificaram que altas demandas de trabalho favorecem o aumento do risco de desordem psiquiátrica e, nesse sentido, indicam a necessidade de estratégias adequadas para prevenir stress e burnout.

Segundo Posig e Kickul (2003), nas duas últimas décadas, o burnout tem sido foco de estudo de diversos pesquisadores, principalmente ligado ao trabalho de profissionais da saúde e educação.

Em estudo realizado por Peeters e Rutte (2005), junto a 123 professores do Ensino Fundamental, os autores concluíram que a combinação de alta demanda de trabalho e baixa autonomia são fatores preditivos para conduzi-los ao burnout, sobretudo com a presença de exaustão emocional e implicações na dimensão da realização pessoal.

Quando essa síndrome acomete os professores, afeta o ambiente escolar e conduz os profissionais à alienação, desumanização e apatia, além de causar problemas de saúde, absenteísmo e ideias de abandono da profissão.

Em estudo realizado por Brewer e Mc Mahan (2003), com educadores de escolas técnicas e industriais, para levantamento de stress e burnout no trabalho, os autores identificaram, como principal fator estressor, a falta de suporteorganizacional.

Em pesquisa realizada por Volpato et al. (2003), em 22 escolas municipais do município de Maringá, com 170 professores (96,5\% do sexo feminino e 3,5\% do sexo masculino), demonstrou-se um maior índice de diminuição da realização pessoal no 
trabalho (33,84\%), seguida por exaustão emocional (27,70\%). A despersonalização foi a dimensão que obteve menor índice, entre os professores (5,76\%).

Lau, Yuen e Chan (2005), em estudo de que participaram 1797 professores (819 homens e 969 mulheres), em Hong Kong, encontraram maiores escores para esgotamento emocional e diminuição da realização pessoal e baixos escores para despersonalização.

Codo (1999), em investigação nacional com cerca de 39.000 trabalhadores da educação, encontrou em $25,1 \%$ dos professores exaustão emocional, em 31,9\%, diminuição da realização pessoal e, em 10,7\%, despersonalização. O mesmo autor alerta que o burnout é um fenômeno disseminado entre os demais profissionais da educação (auxiliares administrativos, secretário, diretor, supervisor de ensino, entre outros), cujos índices de incidência também se mostraram significativos.

Ferenhof e Ferenhof (2002), em trabalho com professores do Ensino Fundamental e Médio de Duque de Caxias - RJ, constataram que, dos 71 participantes, todos apresentavam despersonalização e $67,6 \%$, baixa realização pessoal no trabalho.

Garcia e Benevides-Pereira (2003), pesquisando o ensino superior privado de Maringá, encontraram 19,67\% de exaustão emocional, 37,98\% de diminuição da realização pessoal e 4,97\% de despersonalização.

Barasuol (2004) verificou, em estudo junto a 39 professores (100\% do sexo feminino) de alunos com necessidades educacionais especiais de um município no Rio Grande do Sul, a presença de $27,1 \%$ de diminuição da realização pessoal, $22,9 \%$ de exaustão emocional e $8,8 \%$ de despersonalização.

A partir dessas experiências, observa-se que a presença de indicadores de burnout em professores é um tema enfatizado na literatura; contudo, existe um conjunto de problemas que acomete os professores, os quais podem ser sintetizados em aspectos físicos, emocionais, fatores físicos do ambiente, organizacionais e de infraestrutura escolar. A seguir, é apresentada uma síntese de estudos.

Em relação aos aspectos físicos, é possível mencionar problemas na voz (SMITH et al., 1998; MARIANO; MUNIZ, 2006; PORTO et al., 2004); doenças musculoesqueléticas: (GASPARINI; BARRETO; ASSUNÇÃO, 2005; PORTO et al., 2004); doenças respiratórias e cardiovasculares: (GASPARINI; BARRETO; ASSUNÇÃO, 2005) e cefaleia: (MARIANO; MUNIZ, 2006).

No que concerne aos aspectos emocionais, pode-se destacar a presença de: indicadores de stress: (LIPP, 2002; PRIOSTE, 2006; MARTINS, 2007; REINHOLD, 2001); transtornos psíquicos e de comportamento: (GASPARINI; BARRETO; ASSUNÇÃO, 2005); indicadores de burnout: (MASLACH; JACKSON, 1981; CODO, 1999; NAUJORKS, 2002; CARLOTTO; PALAZZO, 2006; LEVY, 2006).

Outros aspectos estudados na literatura referem-se aos fatores físicos do ambiente, organizacionais e de infraestrutura escolar, tais como: inadequações de 
temperatura, ventilação, iluminação e espaço físico, presença de ruído (MARIANO et al., 2002; MARIANO; MUNIZ, 2006; LEVY, 2006); jornada de trabalho extensa/ sobrecarga de trabalho (OLIVEIRA, 2001; MARIANO; MUNIZ, 2006; ROCHA, 2008; SAMPAIO; MARIN, 2004); baixa remuneração e reconhecimento profissional (REINHOLD, 2001;SAMPAIO; MARIN, 2004); insuficiência ou ausência de materiais, equipamentos e recursos didáticos (SILVA; CARLOTTO, 2003) e insuficiência ou ausência de formação e capacitação de professores (NAUJORKS, 2002).

Dessa forma, é possível afirmar, com base nessa literatura citada, que existe um conjunto de fatores desfavoráveis para o exercício da docência. Nos dizeres de Oliveira (2005, p.1060), a escola “[...] tem se mostrado um espaço gerador de tensões e sofrimentos para os que nela trabalham".

A literatura aponta que tais problemas atingem os professores nos diferentes níveis de ensino, ou seja, infantil, fundamental, médio ou superior. Contudo, uma questão a ser refletida é se esses problemas são semelhantes ou diferentes, de acordo com a modalidade de ensino oferecida, istoé, no ensino regular e especial. Em outras palavras, será que as características dos alunos constituem ou não fator de agravamento das condições de trabalho e, consequentemente, são determinantes de adoecimentos nos professores?

Poder-se-ia supor que, no ensino especial, exige-se maior sobrecarga física em função das suas limitações, tais como falta de coordenação de movimentos, limitações na locomoção, dependência nas atividades de vida diária (autocuidado) e nas atividades educativas. Na mesma direção, isso poderia ocasionar maior desgaste emocional, em função de demandar maior tempo de permanência e envolvimento com o aluno. No entanto, será que essa hipótese se confirma, na prática? A seguir, são apresentados alguns estudos sobre essa temática.

Em estudo realizado por Strassmeier (1992), o autor verificou maior nível destress em professores de alunos com necessidades educacionais especiais, quando comparados aos do ensino comum. Billingsley e Cross (1992), que investigaram a satisfação no trabalho e o stress sentido junto aos alunos (463 professores de alunos com necessidades educacionais especiais e 493 de professores do ensino comum), não constataram diferenças significativas entre os grupos.

De acordo com Meleiro (2007), é muito comum para os professores de alunos especiais o contato com situações geradoras de stress. Malagris (2007) acrescenta que o professor apresenta vulnerabilidade ao stress e, de forma mais intensa, quando lida com crianças que manifestam distúrbios de conduta. Naujorks (2002) acredita que a sobrecarga e o cansaço são mais intensos, nos professores que atuam junto aos alunos com necessidades educacionais especiais.

Barasuol (2004) encontrou, em pesquisa com 39 professores (100\% do sexo feminino) de alunos com necessidades educacionais especiais de um município no Rio Grande do Sul, a presença de 27,1\% de diminuição da realização pessoal, 22,9\% de exaustão emocional e 8, 8\% de despersonalização. 
Stempien e Loeb (2002), observando professores do ensino regular e especial, identificaram a presença de maiores indicadores de insatisfação nos últimos, sendo mais prevalente em professores jovens, com menor tempo de experiência. Lau, Yuen e Chan (2005) identificaram que professores de alunos com habilidade acadêmica mais alta geralmente apresentam menos burnout, mas, em contrapartida, os que ensinam os estudantes com mais baixa habilidade acadêmica obtiveram o mais alto escore em realização pessoal.

Em estudo realizado por Zabel e Zabel (2001), os autores detectaram a existência de correlação entre o trabalho e a presença de fatores estressores dos professores do ensino especial.

Nota-se que os resultados das pesquisas sobre desgaste e/ou satisfação dos professores e a correlação com as características dos alunos atendidos ou modalidade de ensino não apresentam homogeneidade, ora indicando similaridades, ora diferenças. Por que essa literatura aponta nesta direção? Que fatores justificam/ explicam? Uma das vertentes enfatizadas é a formação dos professores.

Para Meleiro (2007), o professor acaba assumindo o papel de gerenciador das diferentes situações presentes no ambiente escolar, mesmo que não disponha do preparo necessário.

Segundo Oliveira (2007), o panorama atual revela um aumento significativo das demandas aos professores, havendo necessidade de um conjunto de competências para dar contar da diversidade de tarefas a serem realizadas.

No entendimento de Malagris (2007), tem-se a expectativa de que os professores detenham habilidades, recursos pedagógicos, e que estes sejam revertidos em prol do processo ensino-aprendizagem, a fim de que o aluno também tenha um desempenho adequado. Porém, não é incomum se defrontar com professores despreparados para lidar com alunos com dificuldades de aprendizagem.

Uma discussão bastante enfatizada, na literatura, é a questão da formação dos professores para atuação no ensino inclusivo.

De acordo com a Resolução CNE/CP 1 (Conselho Nacional de Educação/ Conselho Pleno), de 18 fevereiro de 2002, a formação deverá garantir a constituição de competências na educação básica; desenvolver competências em diferentes âmbitos do conhecimento profissional do professor; prover a seleção de conteúdos nas diferentes etapas da escolaridade, articulados com didáticas específicas; dar autonomia no processo de ensino-aprendizagem e qualificação profissional.

Contudo, Oliveira (2006) enfatiza que, muitas vezes, a formação oferecida aos professores é conservadora, tecnicista e pouco reflexiva. Percebe, igualmente, a presença de investimento no desenvolvimento de competências consideradas já superadas e distantes da realidade escolar. 
Libâneo (2000) entende que existem professores com bom repertório de competências e habilidades profissionais e sociais e com elevado grau de responsabilidade com seu trabalho, mas que, ao se defrontar com as deficiências de formação inicial e/ou continuada, acabam fazendo parte de um universo de professores com preparação insuficiente para dar conta das demandas da profissão, como o domínio de conteúdo e procedimentos de docência, cultura geral e bom senso pedagógico.

Omote (2001) aponta para a existência de uma enorme distância entre a intenção e a realidade das práticas educativas com os deficientes.

Pode-se supor que essa distância também seja o reflexo das diferentes concepções e dúvidas a respeito da formação dos professores. Nesse contexto, é possível afirmar que a formação de professores está permeada por um cenário de indefinições quanto às políticas educacionais, que acaba conduzindo a um universo de professores sem a qualidade profissional necessária.

Oliveira (2004) ressalta a necessidade de cursos de formação que contemplem princípios de educação inclusiva e fundamentos de educação, ou seja, percepção da diversidade, flexibilização da ação pedagógica, identificação das necessidades educacionais, promoção de adaptações curriculares.

Esse panorama - que conjuga, de um lado, as lacunas na formação de professores e dificuldades de lidar com a diversidade de alunos e, de outro, a presença de situações de risco no trabalho do professor, decorrentes de problemas no ambiente e infraestrutura escolar - configura impacto para a saúde física e emocional, no exercício profissional de professores.

A seguir, apresentam-se os resultados de um estudo que buscou comparar a presença de indicadores de burnout, em três grupos de professores que atuam no primeiro ciclo do Ensino Fundamental: a) no ensino regular, em turmas sem a inserção de alunos com necessidades educacionais especiais - RSI; b) no ensino regular, em turmas com a inserção de alunos com necessidades educacionais especiais - RCI; c) em salas de recursos - SR.

\section{MÉTodo}

\subsection{Participantes}

Participaram do estudo 60 professores da Rede Municipal de Ensino Fundamental ( $1^{\mathrm{a}}$ a $4^{\mathrm{a}}$ séries) de Bauru, distribuídos em três grupos: a) 20 professores que atuavam no ensino comum, em turmas sem a inserção de alunos com necessidades educacionais especiais - RSI; b) 20 professores que trabalhavam no ensino comum, em turmas com inserção de alunos com necessidades educacionais especiais - RCI; c) 20 professores que atuavam em salas de recursos - $\mathrm{SR}^{4}$.

\footnotetext{
${ }^{4}$ O projeto foi submetido e aprovado pelo Comitê de Ética em Pesquisa da Universidade Federal de São Carlos, Parecer n 226/2006, em 13 de setembro de 2006.
} 


\subsection{INSTRUMENTO}

Para a coleta, utilizou-se o protocolo Maslach Burnout Inventory (MBI). O MBI foi desenvolvido no início da década de 1980, por Maslach e Jackson (1981). É uma escala composta de 22 itens, com sete possibilidades de respostas $(0=$ nunca; 6 = todo dia) para a intensidade de sintomas do burnout, contemplando: nove itens sobre exaustão emocional, cinco para despersonalização e oito de diminuição da realização pessoal (POSIG; KICKUL, 2003).

A distribuição dos itens por escala é a seguinte:

- Exaustão Emocional: 1,2,3,6,8,13,14,16,20;

- Despersonalização: 5,10,11,15,22

- $\quad$ Diminuição da Realização Pessoal: 4,7,9,12,17,18,19,21.

Contudo, na presente pesquisa, foi empregada a versão do MBI traduzida, adaptada e validada para a realidade brasileira por Tamayo (1997). Na composição dos itens que constituem as escalas, a pontuação utilizada pelo autor foi alterada em relação à versão original, que oferecia sete possibilidades de resposta com escores de 1 a 5 ( 1 = nunca, 2 = algumas vezes ao ano, 3 = algumas vezes ao mês, 4 $=$ algumas vezes por semana e $5=$ diariamente), uma vez que o estudo-piloto com professores revelou dificuldades no instrumento, dado o número de alternativas para mensurar a frequência das respostas.

\subsection{Procedimentos de coleta de dados}

Os procedimentos para a realização da coleta de dados foram:

1. Contato com Secretaria Municipal de Educação, para apresentar os objetivos da pesquisa e solicitar autorização para acesso às instituições de ensino;

2. Contato com as instituições de ensino, a fim de apresentar os objetivos da pesquisa e solicitar colaboração para acesso aos professores/educadores;

3. Contato com os participantes em potencial para apresentar os objetivos da pesquisa e solicitar a colaboração na realização do estudo. Nesse momento, os participantes que concordaram em participar da pesquisa assinaram o termo de consentimento livre e esclarecido;

4. Agendamento do horário e local mais conveniente ao participante e realização das entrevistas.

\subsection{Procedimentos de tratamento e anÁlise de Dados}

Para a análise dos instrumentos, foi usado o pacote SPSS, versão 13.0, e realizado o Teste de Kruskal-Wallis (teste não paramétrico), para comparação dos três grupos. Foi realizado Teste Qui-Quadrado, para os itens que compõem as 
escalas nas quais estão apresentadas as somas dos escores totais obtidos por item para as três dimensões do burnout. Os resultados foram organizados em forma de tabelas. Em todas as análises estatísticas efetivadas para ambos os instrumentos, foram considerados valores de $p \leq 0,05$.

\section{Resultados e Discussão}

Os resultados obtidos serão expostos da seguinte forma:

- Dados demográficos da amostra;

- Dimensões do burnout

- Exaustão emocional;

- Diminuição da realização pessoal;

- Despersonalização.

\subsection{Dados Demográficos}

Os dados da amostra são apresentados na Tabela 1, abaixo:

Tabela 1: Dados demográficos da amostra nos três grupos de professores

\begin{tabular}{|c|c|c|c|c|}
\hline & & RSI & $\mathrm{RCI}$ & SR \\
\hline Idade (média & anos) & 33,6 & 35,8 & 43,7 \\
\hline Tempo na fu & (média em anos) & 9,3 & 9,6 & 10,9 \\
\hline \multirow{4}{*}{ Estado Civil } & Casada & $50 \%$ & $80 \%$ & $60 \%$ \\
\hline & Solteira & $35 \%$ & $15 \%$ & $15 \%$ \\
\hline & Separada & $15 \%$ & $5 \%$ & $20 \%$ \\
\hline & União não formal & -- & -- & $5 \%$ \\
\hline
\end{tabular}

Foi realizada análise estatística, por meio do Teste Qui-quadrado-Crosstabs, para as três variáveis (idade, tempo de função e estado civil), a fim de verificar se havia diferenças estatísticas entre os grupos de professoras. Quanto à idade e tempo na função, não foram identificadas diferenças significativas entre os grupos, sendo 0,123 e 0,329, respectivamente, os valores obtidos de $p$. Na Tabela 1 , a distribuição das ocorrências revela que a média de idade e tempo na função para os professores do grupo SR é de 43 anos de idade e 10,9 anos como docente, seguidos de RCI $(35,8$ / 9,6) e RSI $(33,6$ / 9,3).

A mesma tendência foi observada quanto ao estado civil, uma vez que também não foi encontrada diferença significativa, com valor de $p=0,091$, revelando que, matematicamente, os grupos são equivalentes. Observa-se, na 
Tabela 1, que a frequência de casadas no grupo RCI é de $80 \%, 60 \%$ em SR e $50 \%$ em RSI. A tabela evidencia, ainda, que RSI possui $35 \%$ de solteiras, enquanto RCI e SR apresentaram $15 \%$. As categorias separada ou divorciada é encontrada em $20 \%$ de SR, seguido de RSI (15\%) e RCI (5\%). Apenas uma participante do grupo SR relatou a condição de união não formal.

Um estudo realizado pela UNESCO (2004) sobre o perfil dos professores brasileiros demonstra que $55,1 \%$ se declararam casados e $28,3 \%$, solteiros.

Salienta-se que muitos professores acabam submetidos a uma jornada dupla (de trabalhar em mais de uma escola), em função de compensações salariais (SAMPAIO; MARIN, 2004). Meleiro (2007) destaca a utilização, pelos professores, de horários de descanso e lazer, nos finais de semana, para atividades de correção de provas e trabalhos e preparação de aulas, além de atividades domésticas, sobretudo no caso das professoras.

As atividades domésticas muitas vezes, para as mulheres, configuram uma terceira jornada de trabalho. Bock (2004), em pesquisa empreendida com 33 professores do ensino especial, constata que $96 \%$ das professoras são responsáveis pela realização das atividades domésticas. Em que pesem as considerações acima, não foram encontradas diferenças significativas entre casados e solteiros, na amostra do presente estudo. Por outro lado, a investigação de Lau, Yuen e Chan (2005), junto a professores em Hong Kong, identificou que, no que tange ao estado civil, os solteiros apresentaram maior incidência de burnout, quando comparados aos casados.

Quanto ao gênero, a amostra foi integralmente composta por professoras, ainda que os professores tenham sido igualmente convidados a participar, denotando o predomínio do sexo feminino na rede municipal de Ensino Fundamental no município focalizado. Em estudo realizado pela UNESCO com professores brasileiros, obteve-se que $81,3 \%$ são mulheres e $18,6 \%$ são homens, e que a maioria das professoras atua no Ensino Fundamental. No entanto, a pesquisa conduzida por Lau, Yuen e Chan (2005) constatou diferenças de gênero nas três dimensões da síndrome de burnout, tendo as professoras evidenciado maior ocorrência de exaustão e diminuição da realização pessoal, e menor despersonalização.

Carloto e Palazzo (2006) fizeram levantamento epidemiológico sobre a presença de burnout e fatores associados, com a participação de 190 professores (78,9 \% do sexo feminino) de escolas municipais, estaduais e particulares, em Porto Alegre. As autoras identificaram com maior frequência a presença de exaustão emocional, seguida de diminuição da realização pessoal e, com menor intensidade, de despersonalização. Não foram notadas relações entre as dimensões do burnout e as variáveis demográficas (sexo, idade, número de filhos e estado civil), apesar de a amostra ter sido composta por $64,9 \%$ de casadas. 


\subsection{Dimensões do BuRnout}

\subsubsection{EXAUSTÃo EMOCIONAL}

A Tabela 2 contempla os escores obtidos junto aos três grupos de professores, na escala de exaustão emocional, para os nove itens que a compõem, e as medianas e valores de $p$ :

Tabela 2 - Distribuição dos escores obtidos para a Exaustão Emocional (Teste Kruskal-Wallis)

\begin{tabular}{|c|c|c|c|c|}
\hline Exaustão Emocional & $\begin{array}{c}\text { Mediana } \\
\text { RSI }\end{array}$ & $\begin{array}{c}\text { Mediana } \\
\text { RCI }\end{array}$ & $\begin{array}{c}\text { Mediana } \\
\text { SR }\end{array}$ & Valor de $p$ \\
\hline $\begin{array}{l}1 \text { - Eu me sinto emocionalmente exausto pelo meu } \\
\text { trabalho. }\end{array}$ & 3 & 3 & 3 & 0,239 \\
\hline $\begin{array}{l}2 \text { - Eu me sinto esgotado ao final de um dia de } \\
\text { trabalho. }\end{array}$ & 4 & 3,5 & 3 & $0,045^{*}$ \\
\hline $\begin{array}{l}3 \text { - Eu me sinto cansado, quando me levanto de } \\
\text { manhã e tenho que encarar outro dia de trabalho. }\end{array}$ & 2 & 3 & 2 & 0,508 \\
\hline $\begin{array}{l}6 \text { - Trabalhar com pessoas o dia inteiro é realmente } \\
\text { um grande esforço para mim. }\end{array}$ & 1 & 1 & 1 & 0,814 \\
\hline 8 - Eu me sinto esgotado com meu trabalho. & 2 & 3 & 2 & 0,070 \\
\hline 13 - Eu me sinto frustrado com meu trabalho. & 2 & 2 & 2,5 & 0,582 \\
\hline $\begin{array}{l}14 \text { - Eu sinto que estou trabalhando demais no meu } \\
\text { emprego. }\end{array}$ & 3 & 3 & 2 & 0,177 \\
\hline $\begin{array}{l}16 \text { - Trabalhar diretamente com pessoas me deixa } \\
\text { muito estressado. }\end{array}$ & 2 & 2 & 2 & 0,910 \\
\hline $\begin{array}{l}20 \text { - No meu trabalho, eu me sinto como se estivesse } \\
\text { no final do meu limite. }\end{array}$ & 2 & 2 & 1 & 0,349 \\
\hline Total & 21 & 22,5 & 18,5 & 0,233 \\
\hline
\end{tabular}

Os dados revelam que, de forma geral, na avaliação da escala de Exaustão Emocional, não foram encontradas diferenças estatísticas entre os grupos, com exceção da questão em que foi investigada a sensação de esgotamento, ao final do trabalho, com diferença significativa $(p=0,045)$ em favor do grupo de professores que atuam nas salas de recursos. Dessa forma, o valor menor da mediana (3) indica que estes podem chegar ao final do dia de trabalho com menor carga de cansaço. Também não foi identificada diferença significativa quanto aos valores totais das medianas. 


\subsubsection{Diminuição da Realização Pessoal}

Na Tabela 3, é apresentada a distribuição das medianas obtidas nos itens que compõem a escala de despersonalização, bem como os valores de $p$.

Tabela 3 - Distribuição dos escores obtidos para a Diminuição da Realização Pessoal (Teste Kruskal-Wallis).

\begin{tabular}{|c|c|c|c|c|}
\hline Diminuição da Realização Pessoal* & $\begin{array}{l}\text { Mediana } \\
\text { RSI }\end{array}$ & $\begin{array}{l}\text { Mediana } \\
\text { RCI }\end{array}$ & $\begin{array}{l}\text { Mediana } \\
\text { SR }\end{array}$ & Valor de $p$ \\
\hline $\begin{array}{l}4 \text { - Eu posso entender facilmente o que sentem os } \\
\text { meus alunos acerca das coisas que acontecem no } \\
\text { dia-a-dia. }\end{array}$ & 4 & 4 & 4 & 0,876 \\
\hline $\begin{array}{l}7 \text { - Eu trato de forma adequada os problemas de } \\
\text { meus alunos. }\end{array}$ & 4 & 4 & 4,5 & $0,013^{*}$ \\
\hline $\begin{array}{l}9 \text { - Eu sinto que estou influenciando positivamente } \\
\text { a vida de outras pessoas, através do meu trabalho. }\end{array}$ & 4 & 4 & 5 & $0,042^{*}$ \\
\hline 12 - Eu me sinto muito cheio de energia. & 3 & 3 & 4 & 0,081 \\
\hline $\begin{array}{l}17 \text { - Eu posso criar facilmente um ambiente } \\
\text { tranquilo com os meus alunos. }\end{array}$ & 4 & 4 & 5 & $0,006^{*}$ \\
\hline $\begin{array}{l}18 \text { - Eu me sinto estimulado depois de trabalhar } \\
\text { lado a lado com os meus alunos. }\end{array}$ & 4 & 4 & 5 & 0,063 \\
\hline $\begin{array}{l}19 \text { - Eu tenho realizado muitas coisas importantes, } \\
\text { neste trabalho. }\end{array}$ & 4 & 4 & 4,5 & 0,470 \\
\hline $\begin{array}{l}21 \text { - No meu trabalho, eu lido com os problemas } \\
\text { emocionais com calma. }\end{array}$ & 4 & 4 & 4 & 0,760 \\
\hline Total & 31 & 31 & 36 & $0,050^{*}$ \\
\hline
\end{tabular}

Nota: *Como se trata de uma escala negativa, os escores maiores indicam baixa diminuição da realização pessoal.

Pode-se observar que os três grupos obtiveram altos valores para as medianas. Deve-se ter em vista que, quanto maior o valor da mediana, por se tratar de uma escala negativa, menor a presença do sentimento de diminuição da realização pessoal. Desse modo, os dados sugerem que os três grupos apresentam baixa diminuição da realização pessoal, nesse sentido conseguem lidar com os alunos de maneira adequada, acreditam que seu trabalho influencia positivamente a vida dos alunos e criam um ambiente de trabalho tranquilo.

Todavia, ao comparar os grupos, verifica-se que apenas três itens tiveram significância estatística, isto é, o item $07, \operatorname{com} p=0,013$, o item $09, \operatorname{com} p=0,042$ e o item 17, $\operatorname{com} p=0,006$. Observa-se que a direção da diferença é em favor do grupo de professoras SR, porque, em tais itens, apresentam mediana maior, ou seja, respectivamente, 4,5,5,0, e 5,0. Ressalta-se que, por se tratar de uma escala negativa, quanto maiores os valores das medianas, menor a presença da baixa 
diminuição da realização pessoal. $\mathrm{O}$ mesmo acontece em relação ao valor total de $p=0,050$, cuja diferença significativa indica que SR, com valor total das medianas igual a 36, representa maior frequência sentimentos de realização pessoal com o trabalho, na comparação com RSI e RCI, ambos com valores totais de mediana de 31 para essa escala.

\subsubsection{DeSPERSONALIZAÇÃo}

A Tabela 4 mostra a distribuição das medianas obtidas nos itens que compõem a escala de despersonalização para os diferentes grupos, bem como os valores de $p$.

Tabela 4 - Distribuição dos escores obtidos para a Despersonalização (Teste Kruskal-Wallis).

\begin{tabular}{lcccc}
\hline $\begin{array}{l}\text { Despersonalização } \\
\text { RSI }\end{array}$ & $\begin{array}{c}\text { Mediana } \\
\text { RCI }\end{array}$ & $\begin{array}{c}\text { Mediana } \\
\text { SR }\end{array}$ & Valor de $p$ \\
\hline $\begin{array}{l}5-\text { Eu sinto que trato alguns dos meus } \\
\text { alunos como se eles fossem objetos. }\end{array}$ & 1 & 1 & 1 & 0,329 \\
$\begin{array}{l}10 \text { - Eu sinto que me tornei mais insensível } \\
\text { com as pessoas, desde que comecei este } \\
\text { trabalho. }\end{array}$ & 1 & 1,5 & 1 & 0,091 \\
$\begin{array}{l}11-\text { Eu sinto que este trabalho está me } \\
\text { endurecendo emocionalmente. }\end{array}$ & 1 & 1 & 1 & 0,271 \\
$\begin{array}{l}15-\text { Eu não me importo realmente com o } \\
\text { que acontece com alguns dos meus alunos. }\end{array}$ & 1 & 1 & 1 & 0,802 \\
$\begin{array}{l}22-\text { Eu sinto que os alunos me culpam por } \\
\text { alguns de seus problemas. }\end{array}$ & 1 & 1 & 1 & 0,327 \\
\hline \begin{tabular}{l} 
Total \\
\hline
\end{tabular} & 5 & $\mathbf{5 , 5}$ & $\mathbf{5}$ & $\mathbf{0 , 0 9 7}$ \\
\hline
\end{tabular}

Pode-se observar que não houve diferença significativa na análise por itens e na soma dos escores obtidos, demonstrando um padrão de resposta equivalente entre os grupos. Os valores baixos das medianas obtidos indicam que os três grupos apresentam baixa despersonalização.

Para indicação da presença da síndrome de burnout, a versão original do instrumento, na sua validação, considera uma inter-relação entre as três escalas. Dessa maneira, considera-se o burnout quando o indivíduo obtém grau alto em exaustão emocional e despersonalização, e baixo para diminuição da realização pessoal.

A seguir, apresenta-se a discussão dos resultados por escala do $\mathrm{MBI}$, quanto ao nível baixo, moderado e alto. Vale destacar que, tendo em vista que as opções de resposta (escores) do instrumento são expressas por meio de uma escala 
do tipo Likert, considerou-se a indicação dos escores 1 e 2 (baixa incidência), 3 (moderada) e 4 e 5 (alta).

Na escala de Exaustão Emocional, os dados revelam que o grupo de professoras SR $(61,8 \%)$ obteve os melhores resultados na avaliação, quando comparados com RSI (55,5\%) e RCI (50\%), ou seja, com maior percentual no nível baixo, menor no moderado e menor no alto. Por outro lado, RCI apresentou menor percentual no nível baixo. No nível moderado RSI e RSI apresentaram praticamente o mesmo percentual (35\% e 34,4\%) respectivamente. Em relação ao nível alto, RCI apresentou maior percentual (15,5\%). Assim, no que concerne aos três níveis, há uma ligeira diferença na possibilidade de ter exaustão emocional, quanto ao grupo de professores RCI. Em contrapartida, o grupo de professores SR apresenta menores possibilidades e RSI ocupa posição intermediária.

Para Carlotto (2002), a presença da exaustão emocional nos professores é preocupante, pelo fato de a mesma poder trazer prejuízos na preparação e planejamento de aulas, motivada pela diminuição ou perda da motivação, na criatividade, na empatia, gerando um processo de distanciamento na relação com os alunos.

Volpato et al. (2003) encontraram exaustão emocional em 27,70\% dos professores de Maringá. Garcia e Benevides-Pereira (2003), em estudo igualmente desenvolvido em Maringá, com professores do ensino superior privado, perceberam 19,67\% de exaustão emocional. Codo (1999) constatou valores similares em estudo nacional, em que 25,1\% dos professores apresentaram exaustão emocional.

Vale destacar que a exaustão emocional é considerada uma das primeiras manifestações do burnout, da qual podem advir outros sintomas, como é o caso da despersonalização e diminuição da realização pessoal (CODO, 1999; BENEVIDESPEREIRA, 2002).

Na escala de Despersonalização, a maioria dos professores não demonstrou problemas na dimensão de despersonalização, sendo prevalente o nível baixo, com $96 \%$ em RSI e SR, e 84\%, em RCI. No nível moderado e alto, o grupo de professores RCI foi aquele que obteve os maiores indicadores, com 11\% e 5\%, respectivamente.

Esses dados estão de acordo com os resultados da investigação de Volpato et al. (2003), em Maringá, em que a despersonalização foi a dimensão que obteve menor índice, entre os professores $(5,76)$. Codo (1999) constatou, em estudo nacional, que 10,7\% dos professores apresentaram despersonalização.

A despersonalização é uma dimensão característica da síndrome que a diferencia do stress. Trata-se de uma maneira de o profissional defender-se da carga emocional que ocorre devido ao contato direto com outras pessoas. Dessa forma, o profissional desenvolve atitudes insensíveis em relação às pessoas, no trabalho, defendendo-se de possíveis repercussões dos problemas e sofrimentos alheios em sua vida (VOLPATO et al.,2003). 
Quando essa síndrome acomete professores, ela afeta o ambiente escolar e leva esses profissionais à alienação, desumanização e apatia, além de causar problemas de saúde, absenteísmo e ideias de abandono da profissão.

Na escala de Diminuição da realização pessoal, os três grupos mostraram escores elevados, istoé, RSI (73,7\%), RCI $(79,4 \%)$ eSR $(88,1 \%)$, o que caracteriza nível baixo, já que se trata de uma escala negativa. Entretanto, nos indicadores de nível moderado $(20,6 \%)$ e alto $(5,7 \%)$, o grupo de professores RSI obteve os percentuais mais elevados, denotando maiores sentimentos de frustração, insatisfação, falta motivação, baixa autoestima e autoconfiança, e questionamento da competência profissional.

Na pesquisa de Codo (1999), quase 32\% dos professores exibiram diminuição da realização pessoal. Volpato et al. (2003) encontrou um índice elevado de baixa realização pessoal, no trabalho $(33,84 \%)$, em professores do ensino regular em Maringá. Ferenhof e Ferenhof (2002) identificaram que 67,6\% dos professores de Duque de Caxias - RJ apresentavam baixa realização pessoal no trabalho. Garcia e Benevides-Pereira (2003), em estudo no ensino superior privado de Maringá, encontraram 37,98\% de baixa realização pessoal no trabalho.

Segundo Naujorks e Barasuol (2004), tanto os professores do ensino regular que atuam com alunos cujo desenvolvimento é o esperado, quanto os que trabalham com alunos com deficiências podem apresentar fadiga e desgaste emocional. Entretanto, para a autora, poderia haver um desgaste maior para professores que alunos com deficiências, em função da maior intensidade das demandas pedagógicas e afetivas.

Os dados obtidos na presente pesquisa estão em relativa concordância com os achados dos autores, quando se trata dos professores do ensino regular que atuam com turmas com alunos com deficiências; comparativamente aos demais, houve ligeiro aumento na possibilidade de vulnerabilidade à exaustão emocional. Contudo, é contraditório, ao revelar que os professores dos alunos com alunos com deficiências, ou seja, nas salas de recurso, demonstraram escores menores para a exaustão emocional. Ressalta-se que essa modalidade foi implantada inicialmente no Estado de São Paulo e, atualmente, com a criação das salas de recursos multifuncionais, deve haver expansão no país.

\section{ConClusões}

Os resultados obtidos nesta pesquisa indicaram que, de maneira geral os professores obtiveram uma predominância de escores baixos e médios para a exaustão emocional, baixos para a diminuição da realização pessoal e baixos para a despersonalização. Desse modo, indicam para uma pequena parcela dos docentes apresentou níveis altos de exaustão emocional, RCI (15\%) e RSI $(14,4 \%)$ e SR $(5,5 \%)$. Apenas RCI teve um percentual de 5\%, no nível alto de realização pessoal, e, portanto, esse grupo pode ser referido como aquele que está mais sujeito ao burnout. 
De maneira geral, pode-se apontar para uma relativa similaridade entre os grupos, uma vez que as diferenças existem, porém, são de pequena magnitude. Na comparação entre os grupos, observou-se que SR apresentou, na dimensão da exaustão emocional, maior ocorrência do nível baixo $(61,8 \%)$ e menor no moderado $(32,7 \%)$, o mesmo acontecendo com a diminuição da realização pessoal, em que obteve $88,1 \%$ no nível baixo (cuja escala é negativa e, portanto, quanto maior o valor, melhor o desempenho). Em relação à despersonalização, SR e RSI demonstraram 96\% de ocorrência, no nível baixo. Assim, os dados indicaram que SR manifestou menor incidência de exaustão emocional, maior realização pessoal e baixo índice de despersonalização.

Além disso, RCI apresentou maior incidência no nível alto (com 15,5\%, mas se trata de um percentual que pode ser considerado baixo) e valores similares aos de RSI, no nível moderado (34,4\% e 35\%), na dimensão para exaustão emocional. RSI foi o grupo que apresentou maiores percentuais para o nível moderado $(20,6 \%)$ e alto $(5,7 \%)$, na dimensão de diminuição da realização pessoal. Quanto à despersonalização, RCI foi o grupo que relatou maiores percentuais no escore médio $(11 \%)$ e alto $(5 \%)$, quando comparado aos demais grupos, ainda que esses percentuais possam ser considerados de baixa incidência.

Salienta-se que a exaustão emocional é a primeira dimensão a ser afetada, a qual gradativamente pode desencadear as demais. Segundo Maslach e Leiter (1997), o início de um trabalho, geralmente, é marcado por satisfação e engajamento e, dessa forma, é menos provável que o burnout ocorra nessa fase, sendo os sentimentos gradativamente substituídos por comportamentos e atitudes negativas.

Como consequência da falta de ânimo e energia, o indivíduo desenvolve um afastamento psíquico e emocional dos alunos e de suas relações, podendo atingir inclusive suas relações sociais. Trata-se mais especificamente do elemento despersonalização.

No entanto, a situação se agrava, pois, quando somada ao aspecto exaustão emocional, a despersonalização leva ao comprometimento do desempenho e sensação de incompetência, estabelecendo-se, assim, a redução do sentimento de realização profissional ou ainda baixo envolvimento pessoal no trabalho.

Quanto aos melhores resultados obtidos pelos professores das salas de recursos, é possível levantar algumas hipóteses explicativas. Entre elas, destacamse: os professores escolheram trabalhar com os alunos com deficiências; em geral, receberam a formação específica requerida; havia um número reduzido de alunos; tinha-se maior disponibilidade de recursos didáticos e pedagógicos e, mesmo, compensações salariais.

No caso dos professores do ensino regular, a inserção dos alunos com deficiências se faz de forma obrigatória, mediante o aparato legal, e o professor tem que dar conta dos alunos considerados normais e de alguns que apresentam 
deficiência. Um fator agravante é a manutenção do número de alunos (30 a 40 por sala), o qual, em geral, não diminui com a presença dos alunos com deficiência na sala de aula.

Entretanto, nem sempre as queixas e dificuldades encontradas são, necessariamente, convertidas em adoecimento, o que pode ser constatado nesta pesquisa em que os grupos apresentaram poucos indicadores de exaustão e despersonalização e diminuição da realização pessoal.

Os problemas que permeiam a política e a prática de inclusão escolar esbarram no fato de a difusão de sua implantação e sedimentação dos processos existentes ser gradual e ocorrer de maneira diferenciada, nas instituições escolares, abrigando, desse modo, variados graus de adequação frente às distintas realidades observadas na educação, nas esferas municipais, estaduais e federal.

Sabe-se que muito se avançou, na oferta e efetivação de matrículas de alunos com necessidades educacionais, no ensino regular (BRASIL, 2006; 2008). Apesar desse crescimento, pode-se enfatizar que a legislação ainda não produziu a transformação necessária à realidade escolar, de forma a possibilitar a escolarização bem sucedida de pessoas com necessidades especiais, em classes comuns de escolas regulares.

Há consenso entre pesquisadores e profissionais que lidam com a educação especial sobre a necessidade de se garantir, não apenas o acesso, mas também a permanência e a qualidade no ensino oferecido (SILVA; PEREIRA; ARANHA, 2008).

O processo de inclusão escolar abriga um conjunto de mudanças multifatoriais que envolvem, desde a mudança de concepção da deficiência enquanto elemento social que abriga a universalidade de acesso e equiparação de oportunidades, a transformação do ambiente escolar e da forma de gestão da escola e das pessoas, além das concepções dos professores.

Para Freitas (2004), no perfil do professor formador, deve constar competência para perceber as necessidades educacionais especiais, valorizar a educação inclusiva, flexibilizar a ação pedagógica, a adaptação curricular, os procedimentos didático-pedagógicos e as práticas alternativas às necessidades especiais de aprendizagem, implementando um processo de avaliação contínuo e formação voltada para o trabalho em equipe.

Dessa forma, é preciso considerar o burnout como um fenômeno complexo e multidimensional que agrega aspectos individuais e relativos às condições de trabalho oferecidas aos professores para o exercício profissional.

Não se trata de eleger culpados, mas de buscar soluções de forma conjunta para problemas que interessam a um coletivo. Para Carloto (2002), sua prevenção e erradicação não deve ser tarefa solitária dos professores, devendo reunir esforços entre professores, alunos, instituições de ensino e sociedade. Libâneo (2000) adverte que é preciso considerar as políticas educacionais, os salários baixos, a insuficiente 
formação profissional, as condições de trabalho precárias, a falta de uma estrutura de coordenação e acompanhamento pedagógico.

Em relação aos dados obtidos nesta pesquisa e as divergências e similaridades encontradas em outros estudos, vale ressaltar os dizeres de Moura (1997), ao afirmar que o burnout pode apresentar manifestações e contornos específicos, em função das singularidades presentes na organização e no ambiente de trabalho, bem como nas variáveis socioculturais.

Ainda que os dados não tenham sido contundentes, quanto aos indicadores de burnout nas suas três dimensões, revelaram preocupação com a possibilidade de evolução dos sinais e sintomas e que estes possam, com o decorrer do tempo, transformar-se em condições de adoecimento dos professores, com repercussões, infelizmente, para todos os envolvidos na prestação dos seus serviços.

Dorman (2003) afirma que, para um termo que existe há menos de 30 anos, o burnout se tornou um fator crítico para escolas e sistemas escolares, visto que seus efeitos danosos ao desempenho do professor e à aprendizagem dos alunos não podem ser ignorados pelos empregadores.

Neste sentido, justifica-se a importância do presente estudo, o qual procurou acrescentar novos elementos para a compreensão das condições de trabalho e saúde de professores que atuam no ensino regular e especial. No entanto, alguns fatores limitantes desta pesquisa podem ser mencionados: a utilização de questionários de autoavaliação fechados, como no caso o MBI, que, de um lado, é um instrumento de fácil aplicação, mas não permite ao respondente justificar os motivos da escolha realizada; a importância de um estudo mais amplo, que aborde uma amostra maior de professores, para que os resultados possam ser generalizados. Outro aspecto a ser sinalizado é a escassez de estudos com professores de salas de recursos, o que dificultou a comparação dos resultados obtidos neste estudo, revelando a necessidade de investimento em pesquisa nessa temática.

Contudo, espera-se que os dados apresentados contribuam para compreensão do burnout em professores do ensino regular, com e sem alunos com necessidades educacionais especiais, e/ou suscitem novos encaminhamentos de pesquisas, diante das reflexões que possam ter sido geradas.

\section{REFERÊNCIAS}

BARASUOL, E. B. Burnout docente no trabalho com a inclusão de alunos com necessidades educacionais especiais. 2004. 106f. Dissertação (Mestrado) - Programa de Pós-Graduação em Educação da Universidade Federal de Santa Maria, Santa Maria, 2004.

BENEVIDES-PEREIRA, A. M. T. Burnout: Quando o Trabalho Ameaça o Bem-Estar do Trabalhador. 1. ed. São Paulo: Casa do Psicólogo, 2002. 
BILLINGSLEY, B. S.; CROSS, L. H. Job satisfaction of special education teachers, which is correlated with retention, generally increases with experience, Journal of Special Education, 1992.

BRASIL. Ministério da Educação. Censo Escolar da Educação Básica. Brasília: MEC/INEP, 2008. . Ministério da Educação. Censo Escolar. Brasília: MEC/INEP, 2006.

Professores. CNE/CP. Resolução n.01/02 - Institui Diretrizes Nacionais para a Formação de

BREWER, E. W.; MACMAHAN, J. Job Stress and Burnout among Industrial and Technical Teacher Educators. Journal of Vocational Education Research, v. 28, n. 2, p. 125-140, 2003.

CARLOTTO, M. S. A síndrome do burnout e o trabalho docente. Psicologia em Estudo, Maringá, v.7, n. 1, p. 21-29, 2002.

CARLOTTO, M. S.; PALAZZO, L. S. Síndrome de burnout e fatores associados: um estudo epidemiológico com professores. Cad. Saúde Pública, Rio de Janeiro, v.22, n.5, p.1017-1026, 2006.

CODO, W. (Org.). Educação: carinho e trabalho. 4. ed. Petrópolis: Vozes, 1999.

DEMEROUTI, E. et al. The job demands - resources model of burnout. Journal of Applied Psychology, Michigan. v.86, n. 3, p.499-512, 2001.

DORMAN, J. P. Relationship between school and classroom environment and teacher burnout: a LISREL analysis. Social Psychology of Education, Netherlands , v. 6, p. 107-127, 2003.

FERENHOF, I. A.; FERENHOF, E. A. Burnout em professores. Eccos, São Paulo, v. 4, n. 1, p. 131-151, 2002.

FREITAS, S. N. Formação de professores: interfaces entre a educação e a educação especial. In: MENDES, E. G.; ALMEIDA, M. A.; WILLIANS, L. C. A. (Org.). Temas em Educação Especial - avanços recentes. São Carlos: EDUFSCar, 2004. p.245-250.

GARCIA, L. P.; BENEVIDES-PEREIRA, A. M. T. Investigando o Burnout em professores universitários. Interação Psi, Maringá, v. 1, n. 1, p. 76-89, 2003.

GASPARINI, S. M.; BARRETO, S. M.; ASSUNÇÃO, A. A. O professor, as condições de trabalho e os efeitos sobre sua saúde. Educação e Pesquisa, São Paulo, v. 31, n. 2, p. 189-199, 2005.

LAU, P. S. Y.; YUEN, M. T.; CHAN, R. M. C. Do demographic characteristics make a difference to burnout among Hong Kong secondary school teachers? Social Indicators Research, New York, v. 71, p. 491-516, 2005.

LEVY, G. C. T. M. Avaliação do índice de burnout em professores da rede pública de ensino localizada na Região Sudeste. 2006, 110p. Dissertação (Mestrado) - Universidade do Estado do Rio de Janeiro - UERJ, Rio de Janeiro, 2006.

LIBÂNEO, J. C. Produção de saberes na escola: suspeitas e apostas. In: CANDAU, V. M. (Org.). Didática, currículo e saberes escolares. Rio de Janeiro: DP\&A, 2000.

LIPP, M. E. N. Pesquisas sobre stress no Brasil - saúde, ocupações e grupos de risco. 2. ed. Campinas - SP: Papirus, 2001.

MALAGRIS, L. E. N. O professor, o aluno com distúrbios de conduta e o stress. In: LIPP, M. E. N. O stress do professor. 5. ed. São Paulo: Papirus, 2007, p.42-53. 
MARIANO, M. S. S. et al. Trabalho dos professores da Segunda fase do ensino fundamental: uma atividade coletiva. In: CONGRESSO BRASILEIRO DE ERGONOMIA - ABERGO, 12., 2002. Anais Congresso Brasileiro de Ergonomia... Fortaleza, 2002.

; MUNIZ, H. P. Trabalho docente e saúde: o caso dos professores da segunda fase do ensino fundamental. Rio de Janeiro: Estudos e Pesquisas em Psicologia, Rio de Janeiro, v.6, n.1, p.6-88, 2006.

MARTINS, M. G. T. Sintomas de Stress em Professores Brasileiros. Revista Lusófona de Educação, Lisboa, v. 10, p. 109-128, 2007.

MASLACH, C.; JACKSON, S. E. Maslach Bournout Inventory. Human Services Survey. Palo Alto, CA: Consulting Psychologics Press, 1981.

MELEIRO, A. M. A. S. O stress do professor. In: LIPP, M. E. N. O stress do professor. 5. ed. São Paulo: Papirus, 2007. p.11-27.

MOURA, E. P. G. Saúde mental e trabalho: esgotamento profissional em professores da rede de ensino particular de Pelotas - RS. 1997, 106p. Dissertação (Mestrado) - Pontifícia Universidade Católica do Rio Grande do Sul, Porto Alegre, 1997.

MUROFUSE, N.T.; ABRANCHES, S.S.; NAPOLEÃO, A.A. - Reflexões sobre estresse e Burnout e a relação com a enfermagem. Rev. Latino-Am. Enfermagem, Ribeirão Preto, v.13, p. 255-261, 2005.

NAUJORKS, M. I. Stress e inclusão: indicadores de stress em professores frente a inclusão de alunos com necessidades educacionais especiais. Cadernos de Educação Especial, Santa Maria, v.20, p.117-125, 2002.

; BARASUOL, E. B. Burnout docente no trabalho com a inclusão de alunos com necessidades educacionais especiais. Cadernos de Educação Especial, Santa Maria, n.24, p.97-106, 2004.

OLIVEIRA, A. A. S. Formação de professores em educação especial: a busca de uma direção. In: MENDES, E. G.; ALMEIDA, M. A.; WILLIANS, L. C. A. (Org.). Temas em Educação Especial - avanços recentes. São Carlos: EDUFSCar, 2004. p.239-243.

OLIVEIRA, D. A. A reestruturação do trabalho docente: precarização e flexibilização. Educação e Sociedade, Campinas, v.26, n.92, p.753-775, 2005.

OLIVEIRA, D. A. Política educacional e a re-estruturação do trabalho docente: reflexões sobre o contexto latino-americano. Educação e Sociedade, Campinas, v.28, n.99, p.355-375, 2007.

OLIVEIRA, E. S. G. O "mal-estar docente" como fenômeno da modernidade: os professores no país das maravilhas. Revista Ciência E Cognição, Rio de Janeiro, v.7, p. 27-42, 2006.

OMOTE, S. A concepção da deficiência e formação do profissional em educação especial. In: MARQUEZINE, M. C.; ALMEIDA, M. A.; TANAKA, E.D.O. (Org.). Perspectivas multidisciplinares de Educação Especial II. Londrina: Editora da UEL, 2001. p.45-52.

PEETERS, M. A. G.; RUTTE, C. G. Time management behavior as a moderator of the job demand-control interaction. Journal of Occupational Health Psychology, Washington, v.10, n.1, p.64-75, 2005. 
PORTO, L. A. et al. Doenças ocupacionais em professores atendidos pelo Centro de Estudos da Saúde do Trabalhador - CESAT. Revista Baiana de Saúde Pública, Salvador, v.28, n.1, p.33-39, 2004.

POSIG, M.; KICKUL, J. Extending Our Understanding of Burnout: Test of Integrated Model in Nonservice Occupations. Journal of Occupational Health Psychology, Washington, n.8, n.1, p.3-19, 2003.

PRIOSTE, C. D. Diversidade e adversidades na escola. Queixas e conflitos de professores frente à educação inclusiva. 2006, 164p. Dissertação (Mestrado em Educação) - Faculdade de Educação da Universidade de São Paulo, São Paulo, 2006.

REINHOLD, H. H. O Burnout. In: LIPP, M. E. N. O stress do professor. 5. ed. São Paulo: Papirus, 2007. p.63-80.

. Stress ocupacional do professor. In: LIPP, M. E. N. Pesquisas sobre stress no Brasil saúde, ocupações e grupos de risco. 2. ed. Campinas: Papirus, 2001. p. 169-194.

ROCHA, E. K. G. T. Desigualdade também no adoecimento: Mulheres como o alvo preferencial das síndromes do trabalho. In: ENCONTRO NACIONAL DE ESTUDOS POPULACIONAIS, 16, 2008. Anais... Caxambu, 2008.

SAMPAIO, M. M. F.; MARIN, A. J. Precarização do trabalho docente e seus efeitos sobre as práticas curriculares. Educação e Sociedade. Campinas, v.25, n.89, p.1203-1225, 2004.

SILVA, G. N.; CARLOTTO, M. S. Síndrome de Burnout: um estudo com professores da rede pública. Revista de Psicologia Escolar e Educacional, Campinas, v.7, n.2, p.145-153, 2003.

SILVA, N. R.; PEREIRA, V. A.; ARANHA, M. S. F. Educação inclusiva: o desafio da permanência e garantia da qualidade de ensino In: ___ Igualdade, Diversidade e Educação (mais) inclusiva. São Carlos: Pedro \& João, 2008. p.15-39.

SMITH, E. et al. Voice problems among teachers: Differences by gender and teaching characteristics. Journal of Voice, Philadelphia, v.12, n.3, p.328-334, 1998.

STANSFELD, S. A. et al. Work and psychiatric disorder in the Whitehall II Study. Journal of Psychosomatic Research, Oxford, v.43, n.1, p.73-81, 1997.

STEMPIEN, L. R.; LOEB, R. C. Differences in job satisfaction between general education teachers and special education teachers: implications for retention. Remedial and Special Education, Chapel Hill, North Caroline, v.23, n.5, p.258-67, 2002.

STRASSMEIER W. Stress amongst teachers of children with mental handicaps. International Journal of Rehabilitation Research, New York, v.15, p.235-239, 1992.

TAMAYO, M. R. Relação entre a sindrome de Burnout e os valores organizacionais no pessoal de enfermagem de dois hospitais públicos. 1997, 123f. Dissertação (Mestrado) - Instituto de Psicologia, Universidade de Brasília, 1997.

TRIGO, T. R.; TENG, C. T.; HALLAK, J. E. C. Síndrome de burnout ou estafa profissional e os transtornos psiquiátricos. Rev. Psiq. Clínica. São Paulo, v.34, n.5, p.223-233, 2007.

UNESCO. O perfil dos professores brasileiros: o que fazem, o que pensam, o que almejam. Pesquisa nacional UNESCO. São Paulo: Moderna, 2004.

VASQUES-MENEZES, I.; CODO, W. O que é burnout. In: CODO, W. (Org.). Educação: Carinho e Trabalho. 3. ed. Petrópolis: Vozes, 2002. p. 237-254. 
SILVA, N. R.; ALMEIDA, M. A. .

VOLPATO D. C. et al. Burnout: O desgaste dos professores de Maringá. Revista Eletrônica InterAção Psy, Maringá, v.1, n.1, p.90-101, 2003.

ZABEL, R.; ZABEL, M. K. Revisiting Burnout Among Special Education Teachers: Do age, Experience, and Preparation Still Matter? Teacher Education and Especial Education, Stanford, v.24, n.2, p.128-139, 2001.

Recebido em: 19/04/2011

Reformulado em: 06/09/2011

Aprovado em: 14/10/2011 